\title{
EL PODER (Y LO) SIMBÓLICO
}

\section{Castor Bartolomé*}

\author{
"Cuando Perséfone la deuda antigua de las faltas recoge, \\ de los que murieron, pasados nueve años, \\ las almas envía para el sol del de lo alto. \\ De esas almas los reyes luminosos vienen a formarse, \\ y prestantes varones de elevado saber, \\ que como santos héroes los mortales aquí en la tierra veneran." \\ Mito Órfico
}

\section{Introducción}

El discurso profunda y profusamente técnico y científico de nuestras sociedades pretende imponer una visión de lo socio-histórico en la que prevalece, frente al sentido creado, un supuesto sentido natural descubierto por el saber científico. La verdad objetiva de la sociedad y de sus instituciones sería un descubrimiento del "estrato natural" implícito en el ser de lo socio-histórico, el cual, a su vez, debería ser orientador de toda praxis social. Desde esta perspectiva, cualquier sentido creado sería una construcción irreal sin base en el estrato natural, que inevitablemente lleva la sociedad al voluntarismo, el cual, supuestamente, aboca en el fracaso. Este gran desafío-debate entre el sentido natural y el sentido creado para la sociedad nos Heva a responder y profundizar en cuestiones como: ¿cuáles son los mecanismos que posibilitan que un conjunto de sentidos construidos por el potencial creador del imaginario social, puedan ser constituidos como naturales por el poder instituyente $u$ objetivador de ese mismo imaginario?, ¿cómo se instituye el sentido natural de una sociedad?

Todo sujeto es un sujeto instituido, en gran parte, por las significaciones sociales del poder instituyente u objetivador del imaginario social, las cuales le integraron dentro de una sociedad concreta, con una identidad propia, a lo lar-

* Universidad de Río Grande do Sud, (Brasil). 
go de un complejo proceso de socialización. El poder instituyente del imaginario social hace que el sujeto se objetive al interiorizar el sentido socialmente instituido. Esta objetivación del sujeto es lo que da permanencia y estabilidad a cada sociedad, que, a su vez, la reviste de un carácter de naturalidad y la hace aparentemente incontestable.

Pero nunca se da una socialización total o una objetivación absoluta del sujeto, lo cual significa que el poder instituyente y objetivador del imaginario no es determinante. Ésta es consecuencia de la internalización: cuando el sujeto pregunta el ¿por qué son así las cosas?, la potencialidad creadora del imaginario social interactúa coimplicadamente con el poder instituyente del mismo, relativizando la absolutización de las significaciones instituyentes. La interrogación sobre el por qué de las cosas implica un cuestionamiento sobre su naturaleza. Es la pregunta que interroga al sentido instituido socialmente y abre la posibilidad para la creación de nuevos sentidos. Es la hermeneusis que interpela interpretando las significaciones sociales instituidas: sistemas, estructuras, instituciones, leyes, valores, costumbres, hábitos, normas, creencias, teorías, procedimientos, etc.

\section{El poder legitimador del símbolo}

Cuando la socialización primaria ha conseguido una "casi perfecta adaptación" de la persona a la sociedad, la pregunta por el "por qué" se planteará frente a cuestiones secundarias, pues el sujeto vivenciará lo esencial del sentido instituido como algo natural, que debe ser así por naturaleza, por voluntad de Dios, por tradición, o por la fatalidad del destino.

Cuando se plantea la pregunta por el "por qué" de esta sociedad, se imponen -se ponen consciente o impositivamente-, a través del orden social instituido, mecanismos sociales para contrarrestar el efecto devastador, transformador, que una posición hermenéutica de la realidad -el potencial creador del imaginario- tiene frente a la tendencia conservadora con que el poder instituyente de la sociedad impregna las instituciones sociales, es decir, a todas las significaciones creadas.

Adoptar una postura hermenéutica frente a lo socialmente instituido es someterlo a un proceso de relativización que lo resitúa -lo sitúa relativamenteal nivel del sentido creado y de la naturalidad impuesta. Una vez comprendida la sociedad como un sentido instituido por la potencialidad creadora del imaginario social, la propia sociedad aparece como algo contingente y susceptible de transformación y de modificación por el mismo imaginario que la originó. Entonces el ser humano y la sociedad se instituyen como el punto de creatividad radical de todo sentido socialmente instituido, y la sociedad es concebida como una construcción autónoma. 
Frente a una visión de sociedad que pretende imponerse de forma unívoca a las personas, con un sentido de naturalidad que la hace incuestionable, y, por ese mismo mecanismo, adapta y objetiva las personas a las instituciones y estructuras configurándolas de forma acrítica -sin poner en crisis el sentido instituido-, la hermenéutica se alza como una "amenaza" transformadora que transciende las formas instituidas y se propone como potencialidad creadora de praxis novedosa. Frente a la amenaza desintegradora de la pregunta hermenéutica, que la potencialidad creadora del imaginario social realiza, sobre el ¿por qué las cosas son de esta forma y no de otra? existe un primer mecanismo que intenta neutralizar el potencial transformador del imaginario social: el mecanismo de la legitimación.

La legitimación es un saber socialmente objetivado y asumido que tiene por objetivo justificar el orden socialmente instituido'. Las legitimaciones son respuestas creadas para justificar o neutralizar los diversos interrogantes que cuestionan el ser de una determinada sociedad. El conflicto se establece a nivel de sentidos, es decir, a nivel simbólico. El sentido socialmente instituido tiende a reafirmarse -afirmándose reiteradamente- frente a nuevos sentidos posibles que lo relativizen. Para ello construye una afirmación lógica, racional, natural, científi$\mathrm{ca}$, divina o fatal de las instituciones sociales; lo cual supone resignificarlas simbólicamente con una dimensión transcendente a la relatividad socio-histórica. La lógica no reside pues en las instituciones, sino en el sentido instituido para ellas. La legitimación no se limita ni agota en el nivel del reconocimiento legal, jurídi$\mathrm{co}$, institucional o racional, sino que impregna todos estos aspectos con un sentido que los transciende y los impone como legitimidad simbólica. El objetivo de toda legitimación es siempre, consciente o inconscientemente, ocultar el carácter de realidad creada, relativa, que toda institución y sociedad posee. Pretende ocultar su carácter relativo y dotarle de una legitimación natural-transcendente².

1. Para Habermas: "Legitimidad significa que un ordenamiento político es digno de ser reconocido. Con esa definición se subraya que la legitimidad es una exigencia de validez contestable, y que es (también) del reconocimiento (por lo menos) factual de esa exigencia que depende la estabilidad de un ordenamiento de poder" HABERMAS, J., "Problemas de legitimaçao no Estado Moderno", Para a reconstruçao do Materialismo Histórico, Sao Paulo 1983, p. 219. Según Habermas: "Solamente ordenamientos políticos pueden tener legitimidad y perderla; solamente ellos tienen necesidad de legitimación", HABERMAS, J., "Problemas de legitimaçao..."., p. 220. Cf. también HABERMAS, J., Legitimations im Spätkapitalismus, Frankfurt 1973. En este punto nos diferenciamos de Habermas y ampliamos el concepto de legitimidad más allá del sentido de la legalidad jurídica o institucional, pues entendemos que las relaciones de poder en la sociedad van más allá de las instituciones. Toda forma de poder social se sustenta en algún tipo de legitimación que "transciende" la legalmente establecida o conscientemente expresada, que a su vez es la que verdaderamente da estabilidad y permanencia a las diversas formas de poder dentro de los grupos sociales.

2. En este contexto podemos situar la pretensión de Aristóteles de demostrar que los esclavos son "esclavos por naturaleza (physhéi doûlos)", en confrontación explícita con la argumentación de los sofistas, cf. ARISTÓTELES., Política I, p. 12; 1254 a 16. 
Todo conflicto en torno a las significaciones sociales instituidas es un conflicto de intereses por legitimar o deslegitimar la trama simbólica que las naturaliza y transcendentaliza en una determinada sociedad. El conflicto social, político, económico, étnico, etc., al ser un conflicto de intereses, es un conflicto hermenéutico o simbólico, pues los intereses son construidos a partir de un sentido social instituido, que a su vez los constituye como más importantes que otros o como los intereses por los cuales merece la pena provocar el conflicto ${ }^{3}$.

El sentido socialmente instituido tiene coherencia para aquellos que lo instituyen. Desaparecidos los actores sociales que crearon el sentido, éste permanece en la sociedad, pero ya no es tan evidente como lo fue para aquellos que fueron sus creadores. Por eso, para legitimar el sentido socialmente instituido y perpetuarlo socialmente, se instituyen a su vez nuevas significaciones sociales, esta vez bajo la forma de mecanismos de legitimación del sentido socialmente existente ${ }^{4}$.

La potencialidad creadora del imaginario social tiende a preguntar el "por $q u e^{\prime \prime}$ del sentido socialmente instituido. Como ya vimos, el proceso de socialización pretende significar con un sentido de obviedad o naturalidad a las instituciones sociales; eso permite neutralizar, en gran parte, el potencial hermenéutico-cuestionador del imaginario social. Pero eso, por sí mismo, no es suficiente. Dada la inevitabilidad del potencial creador del imaginario social, que continuamente tiende a interpretar el sentido instituido relativizando las significaciones sociales legitimadas por el mismo, el orden institucional necesita crear diversas fórmulas legitimadoras, instituyendo, así, otro estrato interpretativo sobre la realidad social con el objetivo de protegerla del cuestionamiento hermenéutico del imaginario social. Ese estrato interpretativo legitimador de la realidad social puede ser tanto cognoscitivo como normativo. Estos nuevos sentidos legitimadores son internalizados por las nuevas generaciones durante el proceso de socialización, que a su vez las integra en el orden institucional. Ellos constituyen dimensiones simbólicas que legitiman el orden

3. "Son los intereses, materiales e ideales, no las ideas, quienes dominan inmediatamente la acción de los hombres. Pero las 'imágenes del mundo' creadas por las 'ideas' han determinado, con gran frecuencia, como guardagujas, los raíles en los que la acción se ve empujada por la dinámica de los intereses" WEBER, M., Ensayos sobre sociología de la religión, Madrid 1987, p. 247.

4. Karl Polanyi analiza la organización de los sistemas económicos anteriores al mercantilismo europeo y concluye que: "Dentro de esa estructura, la producción ordenada y la distribución de los bienes se aseguraba a través de una gran variedad de motivaciones individuales, regidas por principios generales de comportamiento. $Y$ entre esas motivaciones el lucro no ocupaba un lugar prominente. Las costumbres y la ley, la magia y la religión cooperaban para inducir al individuo a cumplir reglas de comportamiento, que garantizaban su comportamiento en el sistema económico". POLANYI, K., A grande transformaçao: as origens de nossa época, Rio de Janeiro 1980, p. 69. 
social existente y lo ordenan normatizando los sujetos al mundo de la normalidad existente.

Se instituye una primera forma de legitimación cuando se afirma la lógica interna de las instituciones creadas 5 . Para reforzar un supuesto sentido natural de las instituciones sociales, se las significa con el carácter de autonomía funcional que las justifica en su existencia, en sus medios y en los fines pretendidos. Se afirma que existe una tendencia a la coherencia institucional. Esta coherencia es puesta como un atributo de la propia institución. La socialización realizada a través del propio lenguaje internaliza en el sujeto la convicción de la coherencia funcional de las instituciones sociales existentes ${ }^{6}$.

De hecho, lo más común es que una persona bien socializada vivencie con. sentido de coherencia integradora la sociedad en la que está. Su propia biografía personal es interpretada, normalmente, como un conjunto de acciones discontinuas integradas dentro de un universo subjetivamente significado cuyos sentidos se comparten socialmente a través de actos institucionales. A partir de estos universos de significados socialmente compartidos el sujeto llega a la necesidad de la integración institucional. La institución social no es sentida como un elemento coercitivo que se le impone heterónomamente. Por el contrario, es asumida como parte de su propia identidad personal; ya que ésta es construida a partir de su integración en el orden institucional vigente.

No son los sistemas teóricos artificialmente elaborados para legitimar las instituciones sociales los que más influencia objetivadora ejercen sobre las personas. Éstos, con un mínimo de conciencia crítica, pueden ser interpretados, deslegitimados, con facilidad. El poder legitimador de la sociedad reside, principalmente, en el plano meta-racional, simbólico, que es donde se internalizan los sentidos de forma más natural. Es la legitimación que se instituye a través de los valores, los hábitos socialmente instituidos, las creencias, las costumbres, las normas educativas, etc. Son este tipo de sentidos vitalmente internalizados los que hacen que el sujeto asuma un comportamiento institucionalizado, incorporando como naturales las formas de poder que la sociedad crea? .

Muchas veces no es suficiente para neutralizar la potencialidad creativa del imaginario social establecer un estrato interpretativo que legitime el ser de una sociedad. En tal caso, es común instituir mecanismos de control. Estos mecanismos son a su vez significaciones sociales creadas que tienen por función

5. Sobre los grandes relatos de legitimación social cf. LYOTARD, J. F., La condición posmoderna, Madrid 1989, pp. 95 ss.

6. BERGER, P. L. / LUCKMAM, Th., La construcción social de la realidad, Buenos Aires 1972, p. 85.

7. Sobre la conducta como asimilación de lo dado a esquemas anteriores y como acomodación de los esquemas a la situación actual, cf. PIAGET, J., Seis estudios de psicología, Barcelona 1976, cap. 4. 
reforzar la legitimación del orden social. Tenemos, de esta forma, un segundo estrato interpretativo creado encima del primer sentido instituido por la sociedad. Los mecanismos de control pueden ir desde: estar fuera de moda, el ridículo, la crítica social, el sentirse diferente, el miedo, el desprecio, hasta: la violencia coercitiva de la censura, prisión, represión, tortura o muerte ${ }^{8}$.

Una vez que el poder instituyente del imaginario ha objetivado el sentido social como natural, o sea, como un cuerpo de verdades válidas, de certezas inamovibles, de axiomas naturalmente demostrables sobre la realidad social, todo comportamiento que pretenda reinterpretarlo de forma radical será significado como una desviación de la realidad, que, a su vez, será considerada como una depravación, herejía, rebeldía o ignorancia. Consecuentemente, el hermeneuta creador de nuevos sentidos será significado como un desviante. Tal vez por este motivo no hay lugar para los poetas en la República ideal de Platón.

\section{La legitimación simbólica del poder}

Para comprender en profundidad y en extensión las implicaciones del poder instituyente u objetivador de lo simbólico, es necesario que nos adentremos en una de la dimensiones en que éste se manifiesta de forma más densa y espectacular: la legitimación del poder social. El poder legitimador de lo simbólico se manifiesta en toda su potencialidad e intensidad en la legitimación simbólica del poder. El poder social, como simbolismo instituido y como legitimación simbólica, condensa toda la dinámica y potencialidad a través de la cual el simbolismo legitima el ser de una determinada sociedad, a la vez que, de forma coimplicadora, el poder socialmente instituido legitima el simbolismo social instituyente. El simbolismo y el poder social se coimplican como correferentes, siendo al mismo tiempo instituyentes e instituidos uno por el otro. Por este motivo el poder adquiere una plurivalencia y una multidireccionalidad que abarca tanto la dimensión simbólica como la propia sociedad.

$\mathrm{Al}$ adentrarnos en el espeso entramado de la red simbólica que legitima el poder social, un conjunto de cuestiones vienen a direccionar nuestra reflexión: ¿cómo se articula la relación entre el poder instituyente de lo simbólico v la

8. En las sociedades no diferenciadas, o tradicionales-primitivas, según Balandier: "El desorden no se percibe como encadenamiento de procesos desequilibrantes que culmina en cambios irreversibles, sino como un movimiento, un juego de fuerzas que es necesario dominar para vaciarlo de su carga negativa y emplearlo al servicio del orden. Son principalmente los depósitos simbólicos y rituales, como los que he mostrado, los que efectúan ese retorno, esa transformación del desorden en orden. No hay represión (o hay poca) en el sentido policial moderno, no hay normatización en el sentido burocrático actual; la potencia simbólica -no la del instrumento represivo o correctivo específico- somete al desorden o nutre con él al orden que ella define" BALANDIER, G., El desorden, Barcelona 1988, p. 145. 
legitimación simbólica del poder?, ¿cuales son los mecanismos que el poder usa para legitimarse simbólicamente?, ¿cómo se relacionan la legitimidad simbólica del poder y la racionalidad que lo instrumentaliza? Con este conjunto de cuestiones no pretendemos agotar un tema que por sí sólo sería objeto de un trabajo mucho más extenso. No obstante, nos proponemos el desafío de abordar la institución simbólica del poder, dado que éste es la tecnología social que más compactamente solidifica el poder instituyente del imaginario social.

\subsection{El orden que ordena; la normalidad que normatiza}

La forma más significativa y extendida de legitimación de la realidad social es la creación de un mundo con normas internalizadas, que, a su vez, lo resignifica como el mundo de la normalidad. Esta tendencia a resignificar el ser de la sociedad con el sentido de la normalidad parece denotar una tendencia antropológica que se manifiesta ampliamente en todas las sociedades y en todos los individuos. El ser humano es un ser simbólico que se ve impelido a significar la realidad. El poder instituyente y objetivador del imaginario hace que, a través del sentido instituido, el ser humano tienda a transformar el mundo en cosmos, el caos en orden. Ordenar la realidad conlieva un proceso de identificación con el orden instituido que ordena al sujeto en el orden social por él creado o en el cual se ha socializado. Ésta es una tendencia antropológica derivada de la dimensión simbólica del ser humano. El caos se instituye en orden, el orden se legitima por la norma y la norma se resignifica como la normalidad".

Así pues, el poder simbólico manifiesta una doble dimensión: el poder instituyente $u$ objetivador es instaurador de orden y el potencial creador es relativizador del orden instituido. En un primer momento, el poder instituyente $u$ objetivador de lo simbólico ordena la realidad instituyendo un sentido deter-

9. Queremos dejar constancia que nuestro análisis sobre el poder (y lo) simbólico no pretende indicar una postura axiológica a favor del poder instituyente o de la potencialidad creadora del símbolo -por más que en determinaciones cuestiones o significaciones sociales concretas, analizadas a modo de verificación socio-histórica, sí tomemos posición valorativa sobre las mismas-, sino constatar la realidad antropológica y social de ambas dimensiones y mostrar cómo ellas se manifiestan y estructuran. Que el poder legitimador tienda a conservar e institucionalizar las significaciones no indica, por nuestra parte, que sea un elemento negativo o que deba ser superado, eso dependerá del contexto de cada realidad social y de cada significación instituida. Lo contrario podemos afirmar sobre la posible inducción de una única valoración positiva de la potencialidad creadora del imaginario que de nuestro estudio se pueda derivar. Cualquier valoración positiva o negativa del poder legitimador del símbolo o de la potencialidad creadora del mismo es una valoración personal o social que debe realizarse a partir de cada contexto social determinado. Ambas dimensiones de lo simbólico son esenciales al ser humano y a la sociedad, sin ellas no existiría el sujeto ni la sociedad. Ambas pueden ser instrumentalizadas en una pluridireccionalidad de opciones y en una polivalencia de sentidos. 
minado para todas las cosas. El ser humano no puede relacionarse con la realidad si no es significándola, y en el mismo acto de significar está instituyendo un orden, un sentido determinado para aquello que inicialmente se le presenta sin sentido, insignificante. La creación de sentido implica, necesariamente, la institución de un orden. La constitución del orden que el sujeto y la sociedad realizan al instituir sentido para toda la realidad implica, a su vez, a ambos, dentro del orden por ellos creado, ordenándolos, normatizándolos, dentro del propio orden por ellos instituido. La realidad social también está sujeta a esta función ordenadora del ser humano. Éste no puede vivir ni convivir con el sin sentido, ni con la insignificancia; necesita instituir sentido a todas las cosas, y que todo tenga un significado. Necesita del orden social para sentirse él mismo identificado, ordenado dentro del cosmos, de la sociedad por él instituida. El orden simbólico construido para el mundo, es el mundo que ordena la identidad y el ser del sujeto y de la sociedad. Toda esta función ordenadora, conservadora, de la realidad social es obra del poder instituyente u objetivador del imaginario social, que se identifica con el poder instituyente de lo simbólico.

El ser paradójico de lo simbólico posibilita que al mismo tiempo que el poder simbólico es instaurador de orden, sea cuestionador de la ordenación instituida. El poder del imaginario social posee la potencialidad de interrogar al sentido instituido, a la vez que se deja objetivar, aunque no plenamente, por el mismo. Todo cuestionamiento de las significaciones sociales instituidas presupone un potencial hermenéutico de la realidad.

Una manifestación socio-histórica que evidencia el alcance posible del poder legitimador del símbolo lo constituye la estabilidad y la durabilidad de las diversas formas de dominación social. Esa evidencia socialmente paradójica de la gran permanencia y durabilidad de las diversas formas de dominación es, tal vez, una de las manifestaciones más exponenciales del poder instituyente de lo simbólico -de su poder legitimador-, pues él se realiza y se mantiene contra los intereses de las personas o sociedades implicadas en el mismo.

\subsection{La fuerza y el consentimiento del orden}

Muchas veces, a lo largo de la historia, el ser humano se ha hecho la pregunta de cómo es posible que existan y se perpetúen múltiples formas de dominación social sin que se produzcan reacciones más airadas y vehementes por parte de los dominados. El elemento evidente de toda dominación es la fuerza, que se puede manifestar de muchas formas: la coacción más sutil, la represión institucional o la violencia generalizada. Pero la simple fuerza no consigue explicar la perpetuación histórica de las formas de dominación existentes dentro de una sociedad y entre sociedades.

Nuestra hipótesis es que, junto con la fuerza, la legitimación simbólica del poder, impuesta - puesta inconscientemente en lugar de- por el poder institu- 
yente del imaginario social, es el elemento que permite que la dominación se ejerza con un mínimo de resistencia por parte de los dominados, haciendo que los mecanismos de dominación estén introyectados en ellos y posibilitando que distintas formas de dominación se prolonguen a lo largo de los tiempos.

Incluso autores declaradamente partidarios de la Teoría Crítica, herederos de la llustración, donde se propone a la razón como el único o último elemento explicativo del comportamiento humano y social, reconocen que el asentimiento racionalizado al poder instituido no se explica por sí mismo, sino que es un fenómeno mucho más complejo, que va más allá de la simple racionalidad, sea ésta pura o instrumental. La legitimación del poder y el asentimiento pasivo al mismo no se explican totalmente por mecanismos racionales o ideológicos entendiendo la ideología como una forma de racionalidad instrumental. Son necesarios otros elementos que legitimen de forma más vital y hasta inconsciente las pretensiones de validez de las normas socialmente instituidas ${ }^{10}$.

Toda forma de dominación social está constituida por dos elementos esenciales: la fuerza y el consentimiento. Un poder dominador sustentado única y exclusivamente sobre la violencia de la fuerza genera, inevitablemente, resistencias directas y violentas contra él. Lo cual le hace inestable y, consecuentemente, está abocado a tener una duración frágil y limitada. A su vez, ninguna forma de dominación se impone sobre el puro consentimiento de la misma, es necesaria una fuerza que, como elemento de exterioridad, reafirme mediante la coacción violenta las posibles reacciones de los dominados. No obstante, la estabilidad y durabilidad de una sociedad o grupo social instituido sobre formas de dominación está vinculada más profundamente al consentimiento de los dominados que a la fuerza de los dominadores.

Dejamos de lado la dominación impuesta en los casos extremos de guerras reales o amenazantes, que imponen consentimientos forzados por los dominadores, lo que a su vez hace que sean inestables y poco duraderas en el tiempo. En la casi absoluta mayoría de las sociedades prevalecen dos formas de con-

10. "Por regla general, el asentimiento racionalmente motivado se unirá a una aceptación pasiva, producida por las armas o los bienes, para producir una creencia en la legitimidad cuyos componentes no son sencillos de analizar. Estas aleaciones son interesantes, en la medida en que se constituyen en un indicio de que no basta una entrada en vigor positivista de las normas para asegurar a la larga su vigencia social. La imposición duradera de una norma depende también de si en un contexto tradicional pueden movilizarse razones que alcancen a hacer aparecer cuando menos como justificada la pretensión de validez a los ojos de los destinatarios. Aplicado a las sociedades modernas, esto significa que sin legitimidad no hay lealtad de masas" HABERMAS, J., Moralbewusstsein und kommunikatives Handeln, Frankfurt 1983, p. 72.

Sobre la legitimación del poder cf. HABERMAS, J., "Legitimationsprobleme im modernen Staat", Zur Rekonstruktion des Historischen Materialismus, Frankfurt 1976, pp. 217. ss. cf. también, KUHLMANN, W., "Ist eine philosophische Letztbegründung von Normen möglich?", Funkkolleg Ehik, Studienbegleitbrief 8, Weinheim, 1981, p. 32. 
sentimiento, unas que podríamos considerar espontáneas o inconscientes y otras activas o conscientes.

En la realidad nunca se dan formas puras de consentimiento. No existe un consentimiento totalmente inconsciente, pues éste nunca es plenamente espontáneo dado que siempre hay formas de resistencia de los dominados a los medios de dominación instituidos por la sociedad. Tampoco existe un consentimiento que sea total y activamente consciente, ya que siempre es, al menos en parte, inducido por las significaciones sociales instituidas, que son asimiladas por la persona a través de los diversos mecanismos de socialización.

Asumiendo esta relatividad histórica del consentimiento social de los dominados, constatamos cómo las sociedades se mantienen con una cierta estabilidad y durabilidad sustentadas sobre diversos modos y formas de dominación instituida, que a su vez es socialmente consentida.

La fuerza y el consentimiento tienden a la autoexclusión. Esto parece paradójico ya que afirmamos que ambas son constituyentes de la estabilidad social en las diversas formas de dominación. Pero no lo es cuando pensamos que la estabilidad de una sociedad, o de grupos sociales instituidos bajo formas de dominación, se realiza en una combinación coimplicante de estos dos elementos pero en relación inversa, es decir, a mayor fuerza violenta menor consentimiento y consecuentemente mayor inestabilidad de la sociedad, $y$ viceversa, a mayor consentimiento es menor la fuerza violenta que se necesita para imponerse, lo cual genera mayor estabilidad y durabilidad social. El consentimiento otorgado a las formas de dominación existentes es el elemento principal de la estabilidad y permanencia de una sociedad. Eso provoca el interrogante: ¿cómo el poder del imaginario social, a través del poder instituyente de lo simbólico, construye los modos de consentimiento de los dominados dentro de las diversas sociedades y grupos sociales?

\section{El poder como símbolo de servicio: Los nuevos mitos}

El consentimiento social de los dominados es conseguido a través de la institución simbólica de significaciones sociales que justifican, legitiman, esa dominación y la presentan como necesaria y hasta benévola para ambas partes. Se precisa una fuerte imposición simbólica para que los dominados asuman su dominación de forma consentida. Incluso, podemos afirmar que cuanto mayor y más brutal es la dominación, más necesaria y más impositiva -positivando simbólicamente el valor de la misma- debe ser la simbolización que la justifique.

Para que los dominados consientan de forma espontánea a su dominación, es esencial instituir a la dominación con el simbolismo de servicio. La dominación debe ser resignificada socialmente con un nuevo sentido: el de servicio 
que los dominantes prestan a los dominados. Éste a su vez se legitima y justifica por la "necesaria" diferenciación social. La legitimación simbólica del poder social se realiza mediante la institución del sentido de servicio necesario al conjunto de la sociedad que realizan el conjunto de significaciones sociales instituidas: leyes, normas, clases sociales, instituciones y estructuras, etc. El nuevo sentido de servicio posibilita que el conjunto de significaciones sociales que instituyen la sociedad se interrelacionen y se densifiquen constituyendo una red de sentidos necesarios para la existencia y subsistencia de esa sociedad y del conjunto de personas que la componen. El servicio necesario de las instituciones vigentes al conjunto de la sociedad es un elemento más del complejo formado por la red simbólica que legitima el status quo. Éste es justificado como algo necesario, bueno, natural, que beneficia y está al servicio del conjunto de las personas que forman la sociedad.

La existencia de las clases dominantes es concebida como necesaria para el conjunto de la sociedad, y ellas son significadas como funcionalmente servidoras de los intereses de todos, de tal forma que sin ellas, sin la existencia de la diferenciación social, la sociedad derivaría en un caos y los más perjudicados serían los propios dominados: es el mito de la necesidad funcional. La desigualdad social puede ser legitimada argumentando que hay una diferenciación esencial y natural de inteligencia y capacidades personales entre los dominadores y los dominados: es el mito de la desigualdad intrínseca. $Y$ también es posible legitimar simbólicamente la desigualdad arguyendo que la superioridad de unos es debido al esfuerzo y mayor trabajo personal, y, viceversa, la inferioridad de los otros es debido a su falta de esfuerzo y trabajo: es el mito de la igualdad de oportunidades ${ }^{11}$.

La legitimación simbólica del poder tiene una coherencia eficaz porque, normalmente, los dominadores y los dominados comparten las mismas representaciones simbólicas. No debemos pensar que las significaciones imaginarias sociales que legitiman la dominación son comprendidas por los dominadores de forma hipócrita, es decir, como si ellos fuesen conscientes de los mecanismos legitimadores inherentes al simbolismo social instituido. Por el contrario, en la mayoría de las sociedades, el simbolismo legitimador del poder, socialmente instituido por el poder legitimador de lo simbólico, es compartido por el conjunto de la sociedad. Eso hace que el simbolismo sea real y eficazmente legitimador, pues no se concibe otra forma posible de ser esa sociedad. Las mismas representaciones simbólicas, al ser compartidas por dominadores y dominados, les posibilitan conseguir un consentimiento común voluntario y activo

11. "Cómo le va a cada uno en la vida es fundamentalmente asunto de la suerte o de la gracia, y en una pequeña parte proporcional, quizá también cosa de la habilidad, de la aplicación y de otras virtudes" POPPER, K. R., "A propósito del tema de la libertad", La responsabilidad de vivir, Barcelona 1998, p. 146. 
de las personas y de la sociedad al sentido vehiculado por ellas. De esta manera el simbolismo instituido actúa eficazmente como forma de legitimación del poder social ${ }^{12}$.

Estas relaciones sociales, legitimadas previamente de forma simbólica, son significadas con un sentido de naturalidad, de racionalidad o de transcendentalidad. Eso hace que las relaciones de dominación sean comprendidas como algo natural, racional o transcendente -o las tres dimensiones al mismo tiempo, $y$, consecuentemente, pretender transformarlas es concebido como algo irracional, antinatural o contrario a la voluntad transcendente. El sentido de naturalidad, racionalidad o transcendentalidad hace de las relaciones de poder algo inevitable. La inevitabilidad es un sentido instituido que contribuye, a su vez, a la legitimación del orden social. Ser inevitable significa tener que aceptar la realidad como ella es, lo cual demanda un asentimiento voluntario para la misma, una "obediencia" resignada a la dinámica que ella impone. La inevitabilidad, en cuanto sentido inherente a la construcción simbólica de la realidad como algo natural, racional o transcendente, actúa como elemento que refuerza la legitimación social del orden constituido y las instituciones derivadas del mismo.

Para que exista un equilibrio social es necesario que el servicio entre las clases, simbólicamente instituido, aparezca a su vez como un intercambio de servicios. El servicio que los dominados prestan a los dominantes es evidente en su dominación. A su vez, los dominadores necesariamente deben instituir su papel en la sociedad con un sentido de servicio superior al de los dominados, inalcanzable por parte de éstos e imprescindible para el conjunto de la sociedad. Dado que el servicio de los dominantes es mucho menos tangible que el que prestan los dominados, es necesario revestirlo de una significación transcendente o casi-transcendente, natural o racional. De esta forma, la clase dominante es aquella que en una determinada sociedad controla el poder de lo divino, las fuerzas de la naturaleza, el conocimiento, el saber de la lógica y racionalidad de la naturaleza o la capacidad de aplicación de las técnicas más vanguardistas y sofisticadas ${ }^{13}$. El "servicio" que las clases dominantes prestan es simbólicamente legitimado como algo superior, transcendente o natural, inalcanzable para el resto de los dominados y esencial para la sobrevivencia del grupo.

12. Maurice Godelier analiza la forma de legitimación del poder entre los so y los incas, y cómo, de hecho, se articulan las representaciones comunes del grupo social para legitimar la división de clases y las relaciones de dominación. cf. GODELIER, M., Lo ideal y lo material, Madrid 1990, pp. 188-191.

13. Es conocida la anécdota ocurrida cuando Taylor fue cuestionado por un grupo de trabajadores sobre las repercusiones humanas y sociales en relación a sus métodos de producción, a lo cual él respondio: "Se os paga para que trabajéis, no para que penséis; a otros ya les pagan para pensar" FERRAROTTI, F., Una sociología alternativa, Barcelona 1973, p. 41. 
Por el contrario, los servicios que los dominados prestan son significados con un sentido de inferioridad, trivialidad, banalidad, algo común que no tiene gran valor. Generalmente cuanto más material es el servicio, más desvalorizado es. Eso hace que los propios dominados desvaloricen su dominación y consideren su propio servicio como algo trivial frente a la grandeza del servicio que reciben por parte de los dominadores. Esta inferioridad simbólicamente instituida de los dominados es esencial para el consentimiento de éstos a la dominación social que viven ${ }^{14}$.

La legitimación simbólica del poder todavía se hace más densa e intensa cuando en la mayoría de las sociedades la dominación social no sólo se legitima bajo la significación social del servicio compartido, sino que además se instituye una dependencia simbólica y social de los dominados bajo el vínculo de una deuda. Los dominados no sólo reconocen la legitimación de la desigualdad de clases, sino que se sienten en deuda con los dominadores por los favores o ventajas concedidos por éstos. El abismo que separa el valor simbólico de los servicios prestados por dominadores y dominados hace que éstos se sientan impotentes de corresponder a la transcendentalidad, naturalidad o nivel de conocimiento del servicio prestado por los dominadores. Eso posibilita que estén en una situación de deuda constante y permanente con sus dominadores, ya que nunca alcanzarán a retribuir el nivel del servicio prestado por éstos.

La institución simbólica de la deuda es un refuerzo complementario en la legitimación simbólica del poder. Cada elemento simbólico se integra como refuerzo legitimador de la trama simbólica urdida por el poder instituido, a la vez que lo instituye con un sentido de mayor naturalidad y realismo. El sentido de realismo natural y transcendente permite legitimar las diversas formas de poder haciéndolas, para las sociedades que las viven, casi incuestionables en su esencia. El anonimato del simbolismo legitimador hace que éste actúe de una forma universal, al mismo tiempo que lo hace profundamente eficaz. Actúa de una forma transcendente, porque a pesar de ser instituido social e históricamente, su existencia transciende en gran parte a aquellos que lo crearon, a quienes lo viven y a quienes lo sufren. Esa transcendencia la realiza precisamente por la naturaleza redundante e inadecuda de lo simbólico ${ }^{15}$.

La institución simbólica de la dominación como intercambio de servicios establece un sentido ordenador de la sociedad, que la legitima en su funciona-

14. Jean Baudrillard analiza cómo la sociedad de consumo es un inmenso proceso de producción de "valores signo" cuya función es otorgar rango social y establecer diferencias de clase en una época igualitaria que destruye las diferencias de nacimiento. Cf. BAUDRILLARD, J., Pour une critique de l'économie politique du signe, París 1972.

15. Sobre las diversas formas de transcendentalidad que puede adquirir la legitimación simbólica de la dominación social cf. DUMEZIL, G., Les dieux souverains des Indo-Européens, París 1977, y también BOURDIEU, P., Esquisse d'une théorie de la practique. Précedé de trois études d'ethnologie kabyle, Ginebra 1972. 
miento. El orden instituido es simbolizado como algo esencial a la existencia y a la subsistencia del ser de esa sociedad y de los individuos que la integran. Todos se sienten beneficiados por la ordenación social instituida simbólicamente: las clases dominantes por los privilegios que usufructan, las clases dominadas porque consideran que es la menos mala de las situaciones en que pueden vivir. En este caso, el simbolismo actúa no sólo como legitimador del poder, sino que es un factor esencial para conservar el orden instituido por él mismo.

\section{La inversión simbólica en el orden instituido}

La legitimidad simbólica del poder convierte a éste en orden, hasta tal punto que la cuestión de la legitimación suele ser establecida en la relación que existe entre poder y orden. El poder símbólicamente instituido se transforma en orden social, y en base a ese orden se acuerdan las relaciones sociales. Lo que es instituido como orden se nos muestra como aquello que debe ser, como lo natural o lo normal. La legitimación simbólica genera una realidad instituida que es significada como: lo natural, el orden, lo normal, lo racional, que a su vez es la que legitima las relaciones de poder socialmente constituidas. El poder de los dominadores radica en la capacidad que poseen de instituir simbólicamente el orden social, en torno al cual construyen las relaciones de poder.

El orden es una condición esencial para la legitimación simbólica de una determinada sociedad. El orden y la duración instaurados por el simbolismo son, al mismo tiempo, formas que legitiman el propio simbolismo social. La dimensión ordenadora que el simbolismo posee en la conciencia de las personas se transfiere al ámbito de la sociedad, buscando en ésta un orden que se contraponga al caos. El orden simbólico de lo social da a las personas, principalmente, seguridad. Seguridad frente a lo desconocido, frente al caos, frente a la discontinuidad creada por la fragmentación del sujeto y su comprensión de la sociedad como parte de su exterioridad, lo otro, lo diferente de sí. La discontinuidad experimentada por el sujeto y la sociedad en forma de necesidades y contingencias es suturada simbólicamente por el poder legitimador del símbolo que se legitima en el orden instituido, estableciendo un orden social y dando al sujeto y a la sociedad una sensación transitoria de armonía y continuidad.

El ordenamiento simbólico de la sociedad permite a las personas saber lo que pueden y tienen que hacer, lo que pueden o deben creer, en qué tienen que esperar, a qué deben aspirar, cómo se debe regular y entender el ciclo de nacimiento, existencia, vida y muerte, ordena los comportamientos induciendo a asumir las relaciones interpersonales como un signo de que la sociedad funciona porque funciona así. Lo contrario, el caos, el desorden, es algo contra lo que el ser humano lucha desde la institución de las primeras significaciones imaginarias personales que tienen como objetivo representar significativamen- 
te a un mundo que en caso contrario sería totalmente caótico. El orden tranquiliza, da seguridad, alivia la experiencia de discontinuidad fragmentada y eso legitima, todavía más, el simbolismo de las relaciones de poder socialmente instituidas.

Una vez que el poder instituyente de lo simbólico ha legitimado y consolidado el poder socialmente instituido, se establecen nuevas significaciones sociales, mecanismos, para que los propios dominados puedan vivenciar las ventajas de consentir al orden instituido. Los dominados que consienten en el orden instituido invierten en el mismo para poder crecer dentro de él. Es un valor de inversión en el orden vigente, que hace que la legitimación simbólica opere como beneficiadora, también, de los dominados ${ }^{16}$. Este valor de inversión en el orden instituido se hace de forma cotidiana a través de las acciones y opciones vitales que apuestan por integrarse más y mejor en el orden establecido con el objetivo de progresar y crecer personalmente dentro del mismo.

Estas inversiones cotidianas son realizadas también por las clases dominadas, que ante la naturalidad o fatalidad con que el orden social se les impone, apuestan por integrarse lo mejor posible dentro del mismo. Buscan crecer y progresar individualmente invirtiendo en las posibilidades que el orden social les ofrece, hasta el extremo de identificar su seguridad e interés personal con el orden establecido. Ellos mismos son los primeros en defender y defenderse de cualquier intento de transformación del orden establecido; buscan preservarlo, conservarlo, y cualquier intento de transformación del mismo es interpretado, en muchos casos, como una inseguridad o una agresión contra la inversión de intereses y valores que habían realizado en el orden instituido ${ }^{17}$. Aquí tenemos la explicación de muchos comportamientos de conservadurismo social, inexplicables desde una perspectiva puramente racional o crítica.

Este mecanismo de inversión legitima simbólicamente, también ante los dominados, el orden socialmente construido, pues éstos hacen una apuesta vital y existencial por el mismo. No obstante, y al mismo tiempo, por parte de las clases dominantes se instituyen mecanismos para poder reprimir, repudiar o neutralizar cualquier intento de resignificación transformadora del simbolismo legítimamente instituido.

\section{El poder de mando y el poder normatizador}

El poder, por el mecanismo de la legitimación, se transforma en orden. El orden, a su vez, es la institucionalización social del poder. La ordenación de las relaciones implica la formalización de las relaciones de poder. El poder no se

16. POPITZ, H., "Prozesse der Machtbildung", Recht und Staat, Tubinga, (1968), pp. 362-363.

17. LECHNER, N., La conflictiva y nunca acabada construcción del orden deseado, Madrid 1986. 
impone simplemente por la fuerza, ni convence sólo racionalmente de su legitimidad. Su imposición se realiza de forma simbólica mediante la aceptación social de las significaciones socialmente instituidas que legitiman las instituciones y los mecanismos de ejercicio del mismo. El poder legitimador del símbolo transforma el ejercicio del poder social en un ordenamiento, entendido éste en el doble sentido de la palabra "orden": mandamiento y norma. El poder ordena, es decir, crea orden. El orden es legitimado por la aceptación social del simbolismo en el cual se transmuta. De esta forma, el orden no es otra cosa que una forma institucionalizada del poder que se legitima como natural, racional o transcendental por la fuerza de las significaciones sociales instituidas.

La doble dimensión ordenadora del poder social, como mandamiento y norma, deviene en un doble ejercicio posible de ese poder social: el poder que manda como fuerza impuesta, y el poder que normatiza como gobierno de las personas.

El poder que manda se ejerce de una forma impositiva, autoritaria, directa, personal e incluso hasta dictatorial; es el poder que se centraliza en una persona, que lo ejerce de forma impositiva sobre sus subordinados o súbditos. Éstos son coaccionados de forma explícita a cumplir los mandatos emanados del poder, en la mayoría de las ocasiones contra su voluntad o doblegando su voluntad rebelde a través de coacciones externas, generalmente físicas. El poder como mandato ha sido hegemónico en la mayoría de las sociedades premodernas, lo cual no quiere decir que no se ejerza en muchas de nuestras actuales sociedades o en muchas de las instituciones o relaciones de una sociedad.

El poder normatizador se ejerce de forma más sutil. No se impone por la coacción física, sino por la obligación moral. No se ejerce centralizado por una persona, sino que se difumina en el anonimato de las instituciones, normas, costumbres, tradiciones, leyes, valores, creencias, etc. No se comprende como una intimidación extrínseca, sino como un deber de la conciencia personal. El poder normatizador no intenta violentar personas, sino inducir voluntades; no quiere coaccionar al sujeto, sino gobernarlo; no pretende intimidar con el miedo, sino adiestrar la conciencia; su objetivo no es crear esclavos, sino personas obedientes; no se impone como una heteronomía autoritaria, sino que se acepta como un deber moral; no obliga por el castigo físico, sino que normatiza por la ley; no se ejerce como opresión de personas, sino como educación de conciencias y de hábitos; no se manifiesta como tiranía exterior, sino como valores asumidos. Este poder normatizador no pretende mandar despóticamente, coactivamente, sobre los sujetos o los colectivos, sino que busca regular sus comportamientos de forma que ellos mismos se autorregulen ajustándose de forma eficaz a los criterios del poder socialmente instituido.

El poder despótico del mando coactivo no consigue eficacia en la calidad de la acción de los súbditos, sólo les arrebata su fuerza de trabajo bruta o les impone una obediencia servil, pero la conciencia, los sentimientos y la volun- 
tad de los súbditos no se someten, generalmente, a la voluntad del poder, ni a los criterios por él exigidos, con lo cual siempre existe una resistencia larvada, implícita o explícita contra el poder de mando, que repercute directamente en la calidad del trabajo realizado por los súbditos o en la fiabilidad de su sumisión y fidelidad. Por el contrario, el poder normatizador gana efectividad en su aplicación sobre los ciudadanos y eficacia cualitativa en la autorregulación comportamental que la persona o los colectivos hacen de sí mismos en cuanto: obreros, alumnos, funcionarios, ciudadanos, consumidores, etc., según la cosmovisión construida por el orden instituido. Por este motivo el poder normatizador no es un poder que pretenda mandar a las personas con autoritarismo, sino gobernarlas con inteligencia sutil. Este es el poder social que se ha ido construyendo de forma hegemónica en las sociedades llamadas modernas o racionales.

Todo poder, cualquier tipo o forma de poder, no se realiza en una sola dirección, de arriba para abajo, o del centro para la periferia, sino que se proyecta a través de todo el tejido social en una compleja red de relaciones donde dominantes y dominados participan y ejercen relaciones de poder según los diversos medios y posiciones institucionales y estructurales que ocupan ${ }^{18}$.

\section{Invisibilidad de los mecanismos del poder}

Este ejercicio del poder de forma multidireccional solamente es posible por la aceptación colectiva del simbolismo legitimador del mismo ${ }^{19}$. La fuerza normativa del ejercicio del poder, principalmente el poder normatizador o de gobierno, está en una cierta invisibilidad, es decir, en la inconsciencia con la

18. "No considerar el poder como un fenómeno de dominación masiva, homogénea de un individuo sobre los otros, de un grupo sobre los otros, de una clase sobre las otras; sino tener bien presente que el poder, si no se contempla desde demasiado lejos, no es algo dividido entre los que lo poseen, los que lo detentan exclusivamente y los que no lo tienen y lo soportan. EI poder tiene que ser analizado como algo que circula, o más bien, como algo que no funciona sino en cadena." FOUCAULT, M., Microfísica del poder, Madrid 1980, p.p.. 143-144.

19. "Tanto quien 'participa' en el poder como quien 'reivindica' el poder, está justificando al propio poder, y de ello conviene ser conscientes. Los sindicatos o asociaciones de tipo asistencial o de consumidores, si no cuestionan la estructura en que se encuentran, es porque la aceptan como inevitable o incluso como deseable. Quienes ponen en cuestión tal estructura del sistema de poderes tienen otros dos caminos: negar tal poder y construir uno alternativo, como los 'insumisos' frente al ejército, o bien ser 'reversivos' tal como algunos grupos ecologistas, que utilizan la legislación o la moda de lo natural para atacar puntos vitales del sistema de acumulación. La diferencia está en que las conductas 'reversivas' toman principios proclamados por la mayoría de la sociedad (defensa de la calidad de vida, por ejemplo) para desbordar en la práctica al sistema (mostrar el despilfarro del productivismo, construir otros valores)" VILLASANTE, T. R., Las democracias participativas. De la participación ciudadana a las alternativas de la sociedad, Madrid 1995. 
que se ejerce o se acepta. Es la inconsciencia de la invisibilidad, el mecanismo por el cual el poder se torna "normal", se naturaliza y se hace espontáneo al ser de la sociedad y de las personas que lo ejercen. Invisibilidad no del poder, sino de los mecanismos que lo legitiman. Un elemento de poder social puede ser público y evidente, pero los mecanismos o tecnologías que lo legitiman socialmente y que lo hacen natural, legal, normal, transcendente, racional, etc., permanecen ocultos a la exposición pública del poder. La fuerza normativa del simbolismo legitimador del poder radica en el ordenamiento a que somete a la realidad social y a las personas sin tener conciencia de ello. Él mismo construye pautas de comportamiento y formas de ser que instituyen la identidad del grupo y, en cuanto tal, dan lugar a la cohesión del mismo. La inconsciencia e invisibilidad con que el simbolismo legitimador del poder se impone a la sociedad le permite revestirse con una significación de naturalidad que, a su vez, le instituye con un carácter de estabilidad y permanencia.

La invisibilidad del poder no quiere decir invisibilidad de los elementos o de los núcleos hegemónicos del poder. De hecho, históricamente, han prevalecido las manifestaciones visibles, ritualizadas, de los elementos del poder y de aquellos que los ostentan, desde la ritualización sacral del poder babilónico o egipcio, a las manifestaciones ostentosas del absolutismo real, pasando por las paradas militares de todo tipo, hasta el actual predominio hegemónico de la imagen como forma de conseguir la victoria en las elecciones partidarias y de sustentar el índice de popularidad una vez conseguida la victoria. En todas estas manifestaciones exteriores del poder existe una exhibición formal y ostentosa del mismo y de aquellos que lo ejercen. Toda manifestación externa de poder conlleva, necesariamente, una ritualización simbólica de la misma ${ }^{20}$. La desigualdad social es real, pero la construcción de esa desigualdad como algo natural, racional, transcendente, o del candidato como el más inteligente, simpático, popular, capaz, etc., esa es una construcción simbólica ${ }^{21}$.

Que exista una manifestación pública y ostentosa del poder no significa que haya conciencia de los mecanismos a través de los cuales se instituye, ejerce y legitima. Por el contrario, la inconsciencia de los mecanismos y formas por las cuales el poder se instituye y consolida en una sociedad es lo que da a éste estabilidad y solidez. Por eso podemos decir que el poder, en gran medida, es invisible; porque no se tiene consciencia real de los mecanismos a través de los cuales se impone en un determinada sociedad. La legitimación simbólica utilizada por el poder instituyente posibilita extender un tupido velo de incons-

20. Sobre la utilización de símbolos en la construcción social del poder cf. MANIS, J. y MELTZER, B., Symbolic interaction, Boston 1967. Destacamos especialmente el artículo de GARFINKEL, H. "Condictions of succesful degradation ceremonies" sobre la estigmatización simbólica de los "enemigos del orden".

21. BARTRA, R., Las redes imaginarias del poder político, México 1981, p.p. 50 ss. 
ciencia e invisibilidad sobre el poder instituido en una sociedad. Sólo el poder legitimador de lo simbólico puede realizar una legitimación simbólica, real, del poder. Las explicaciones racionales o tecnocráticas resultan insuficientes para comprender y explicar plenamente la invisibilidad e inconsciencia con que el poder se instituye, legitima y ejerce en una determinada sociedad. Esta inconsciencia no es sólo de las clases o grupos dominados, sino que, en gran medida, lo es también de las clases o grupos dominantes.

\section{El poder simbólico de la verdad}

No es objetivo de nuestro trabajo analizar los mecanismos o formas de legitimación del poder en la sociedad actual, sino realizar un estudio de la importancia decisiva del simbolismo en la legitimación de las formas de poder existentes en toda sociedad ${ }^{22}$. No obstante, queremos destacar y reflexionar sobre la importancia creciente de la construcción de los diversos saberes como significación legitimadora del poder en la sociedad actual.

En las sociedades tradicionales ${ }^{23}$, el poder se legitimaba principalmente por el origen superior o divino de aquellos que lo ejercían o por la ostentación pública de la fuerza que imponía el mismo. Las nuevas significaciones sociales construidas por la modernidad destituyeron de sentido, en gran parte, a todo simbolismo sacral del poder, así como instituyeron la igualdad formal de todas las personas, independientemente del nacimiento. Al mismo tiempo, el poder instituyente del imaginario social de la modernidad constituyó la significación de la democracia como poder emanado del pueblo y ejercido en su nombre, lo cual deslegitima de entrada cualquier forma de poder autoritario o impuesto contra la voluntad de la mayoría. Todas estas legitimaciones de igualdad formal chocan, a veces aberrantemente, con las contradicciones de las Ilamadas sociedades democráticas, como son sus enormes desigualdades sociales, una megaconcentración del ejercicio del poder, minorías económicas y políticas

22. Sobre las formas y mecanismos de poder construidos por la modernidad cf. FOUCAULT, M., Surveiller et punir, París 1975; ld., Résumés des cours, París 1989; Id. "Introducción", The history of sexuality, Vol. I, Londres 1979.

23. Entendemos el concepto de sociedades tradicionales según Habermas, que las diferencia de las llamadas sociedades primitivas en: "1) por la existencia de hecho de un poder central de dominación (organización estatal del poder, en oposición a la organización de las tribus); 2) por la separación de la sociedad en clases socioeconómicas (distribución de las cargas y de las compensaciones sociales entre los individuos, de acuerdo con las clases a que pertenecen, y no según los criterios de las relaciones de parentesco); 3) por el hecho de estar en vigencia una imagen central del mundo (mito, religión avanzada) con el fin de legitimar eficazmente el poder" cf. HABERMAS, J., "Técnica e ciência como ideologia", en BENJAMIN, HORKHEIMER, ADORNO, HABERMAS,. Os pensadores. Textos escolhidos, Sao Paulo 1975, p. 233. Sobre el papel predominante de los vínculos familiares en las sociedades tradicionales cf. WEBER, M., Economía y sociedad, México 1984, p. 306. 
actuando en beneficio propio con un mínimo poder de decisión del pueblo, grandes masas de excluidos sociales, muchos grupos sociales marginados por diversos motivos, se perpetúan las diversas formas de explotación económica, etc. Incluso la(s) potencia(s) hegemónicamente democrática(s) no tienen ningún escrúpulo en diseñar una geoestrategia imperialista de dominación neocolonial en el nuevo orden internacional ${ }^{24}$. Las sociedades Ilamadas democráticas han establecido una reserva de riqueza y un muro de exclusión entre las clases dominantes y los dominados, entre los países ricos y los pobres. En ellas los mecanismos del poder continúan actuando a través de una cierta forma de invisibilidad e inconsciencia ${ }^{25}$.

Uno de los principales símbolos instituidos por la modernidad como mecanismo de legitimación del poder es la significación de verdad ${ }^{26}$. Todas las formas de poder construyeron legitimaciones discursivas de su verdad, pero en la modernidad la verdad adquiere una importancia todavía mayor, una autonomía propia y una fuerza especial que le permite imponerse, ella misma, como forma hegemónica de poder. La verdad de la modernidad es construida discursivamente a través de la argumentación científica, de conceptos técnicos o en forma de estadísticas que legitiman la actuación de aquellos que la crean. De esta forma la verdad se impone como algo necesario e incontestable, que el conjunto de la sociedad debe aceptar ${ }^{27}$. Un ejemplo claro de lo que afirmamos lo constituyen el desarrollo de la absoluta mayoría de las políticas económicas o sociales, las cuales son legitimadas a través de un discurso técnico que se fundamenta en la verdad científica, racional y natural que las valida como las mejores posibles, las únicas de acuerdo a las leyes naturales de la economía o de la sociedad, las que mejor se adaptan a la realidad inconmensurable de las

24. Nos parece muy oportuno el concepto de "democracia parlarrentaria" acuñado por Ortiz-Osés para caracterizar el sentido de nuestros actuales sistemas políticos. cf. ORTIZ-OSÉS, A., La nueva filosofía hermenéutica, Barcelona 1986, p. 10.

25. La moda es uno de los mecanismos a través de los cuales las actuales sociedades legitiman un poder que no parece evidente ni visible, sino que actúa de forma invisible e inconsciente: "La moda, como la cultura de masa, habla a todos para poner mejor a cada cual en su lugar. Es una de las instituciones que restituye mejor, que fundamenta con pretexto de abolirla, la desigualdad cultural y la discriminación social. Pretende estar por encima de la lógica social, ser una especie de segunda naturaleza: de hecho está por entero regida por la estrategia social de clase." BAUDRILLARD, J., "Función-signo y lógica de clase", Crítica de la economía política del signo, Madrid 1979, p.p. 33-34. Id., La societé de consommation, París, 1970. Sobre el papel legitimador de la moda cf. BOURDIEU, P., La distinction, París 1979; PERROT, Ph., Les dessus et les dessous de la burgeoisie, París 1981.

26. Sobre cómo la modernidad elabora formas discursivas que construyen la verdad como poder cf. FOUCAULT, M., "La política de la salud en el siglo XVIII", Saber y verdad, Madrid 1985, p.p. 89-106; Id. "La cuestión del método", Tecnologías del yo, Barcelona 1991, pp. 9-44.

27. CONILL, J., "De Adam Smith 'al imperialismo económico'", Claves, 66 (1996), pp. 52-56. 
estructuras o coyunturas existentes, etc. La verdad que legitima el discurso económico o político actual es presentada como algo inherente al mismo, y entendida o explicada como la forma más científica, técnica, racional o natural posible de ejercicio del poder, fuera de la cual sólo existe la incertidumbre del caos.

Otro mecanismo que contribuye a condensar la intrincada trama de la legitimación de la verdad, que a su vez densifica la complejidad simbólica que legitima el poder, es la difusión. La verdad producida por el poder es objeto de una constante campaña de difusión por todos los medios posibles de comunicación social $^{28}$. El poder de difusión es, en la mayoría de los casos, directamente proporcional al poder simbólico que adquiere la significación de la verdad, es decir, la intensidad simbólica de la verdad social está unida al poder de difusión de la misma a través de los diversos medios de comunicación. La verdad se impone, en gran parte, por la amplitud con que es divulgada, así como cualquier otra verdad pierde poder simbólico en la medida que se consigue impedir su divulgación.

Entre la variedad de mecanismos y tecnologías que nuestras sociedades usan para urdir la malla legitimadora de la verdad socialmente instituida como la verdad auténtica, la mejor verdad, la única verdad, la verdad total, como la VERDAD, debemos mencionar -aunque no nos extendamos en su análisis- los que llamamos tribunales de la verdad. La verdad construida, además de ser divulgada, debe ser legitimada por la autoridad simbólica que determinadas instituciones del saber le confieren, instituciones que a su vez están legitimadas en cuanto tales en la sociedad: universidades, libros, autores, debates, periodistas, etc. Para que la verdad socialmente construida sea acogida en una sociedad como la VERDAD, son instituidas diversas formas de legitimación social de la misma que sirven como tribunales refrendadores y divulgadores de una verdad, de un discurso o de un saber ${ }^{29}$. Esos tribunales de la verdad, creados por el orden social vigente, sirven para reforzar la trama simbólica del orden social instituido: premios Nobel, premios Cervantes, premios Príncipe de Asturias,

28. Sobre el papel legitimador de la realidad y conformador de la conciencia que tienen los medios de comunicación en nuestro modelo de sociedad, cf. COLLON, M., ¡Ojo con los media!, Hondarribia 1990.

29. "La verdad es de este mundo; está producida aquí gracias a múltiples imposiciones. Tiene aquí efectos reglamentados de poder. Cada sociedad tiene su régimen de verdad, su 'política general de verdad'; es decir, los tipos de discursos que ella recoge y hace funcionar como verdaderos; los mecanismos y las instancias que permiten distinguir los enunciados verdaderos o falsos, la manera de sancionar unos y otros; las técnicas y los procedimientos que son valorizados para la obtención de la verdad; el estatuto de aquellos encargados de decir qué es lo que funciona como verdadero". FOUCAULT, M., "Verdad y poder", Microfísica del poder, Madrid 1980, p. 187. 
Reales Academias, títulos docentes, títulos honoríficos, etc ${ }^{30}$. La relación existente entre la legitimación simbólica del poder, el orden social instituido y los diversos y plurales mecanismos legitimadores de ese orden -entre los que se encuentra la verdad socialmente instituida y los tribunales que legitiman esa verdad- no es una relación circular uniforme, que contribuya a construir un caparazón inamovible de legitimaciones o una malla tan espesa de sentidos que impida la deconstrucción de la misma o haga inviable la construcción de nuevas redes significativas. Por el contrario, esa relación es una reacción coimplicante donde la legitimación simbólica del poder, el orden social instituido que lo legitima y los mecanismos usados, aunque no lo pretendan o quieran impedirlo, se abren en forma de abanicos a nuevas y novedosas posibilidades de ser la sociedad, lo cual hace factible la recreación de nuevos sentidos más allá de la intencionalidad prevista por los centros hegemónicos del poder o por el sentido inducido a través del poder simbólico.

La verdad es construida con argumentación lógica, científica, técnica. Pero la fuerza de su imposición, en cuanto forma de poder, no reside tanto en la calidad de la argumentación, que también es importante para legitimarse socialmente, sino en el simbolismo que ella adquiere ${ }^{31}$. El proceso de fragmentación del saber, que viene aconteciendo desde los inicios de la modernidad, hace que cada vez mayor número de especialistas, técnicos, sepan más de menos cosas. En este punto, el saber y la verdad por él construida son tarea de grandes especialistas. El saber creado por los técnicos no resulta comprensible para el con-

30. Uno de los instrumentos de legitimación social de los saberes y de su constitución como saber socialmente asumido son las diversas formas institucionalizadas de premio. Un ejemplo del carácter legitimador de los saberes, construidos por estas tecnologías del premio, es la relatividad manifiesta de los premios Nobel de economía, que en las últimas décadas legitimaron prioritariamente los saberes y discursos que presentaban como ciencia objetiva el descubrimiento de nuevas leyes y mecanismos naturales de funcionamiento del mercado; cientificidad que, entre otros muchos ejemplos, se ha visto desmascarada por el fracaso estrepitoso y consecuente quiebra económica, en 1998, del megafondo de inversiones, Long Term Capital Management, gerenciado por los premios Nobel de economía de 1997, Robert Merton y Myron Scholes, que precisamente recibieron tal premio por sus grandes trabajos teóricos sobre evaluación de derivados o inversionés en opciones, ocasionando un problema de credibilidad general a todo el sistema financiero americano. Tal vez para compensar esta tendencia hegemónica de cientificismo naturalista de los premios Nobel, se ha concedido el premio Nobel de economía de 1998 a Amartya Sen, de origen indio, por sus trabajos teóricos sobre una nueva comprensión de los conceptos de miseria, hambre, pobreza y bien-estar.

31. "Hay un combate por la verdad o, al menos, en torno de la verdad -entendiéndose, una vez más, que por verdad no quiero decir "el conjunto de cosas verdaderas a descubrir o acep-

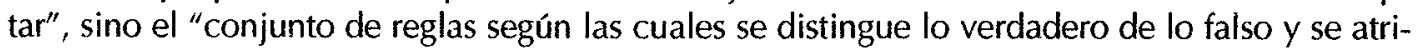
buye a lo verdadero efectos específicos de poder"; entendiéndose también que no se trata de un combate en favor de la verdad, sino alrededor del estatuto de la verdad y del papel económico-político que ella desempeña." MACHADO, R., "Introducción", en FOUCAULT, M., Microfísica del poder, Río de Janeiro 1993, p. 13. 
junto de la sociedad, ni siquiera para los técnicos de otras áreas. El nivel de comprensión y discusión lógica y argumentativa del discurso construido por un saber profundamente fragmentado y tecnificado sólo se realiza entre una minoría de técnicos detentadores de ese saber. Dada la fragmentación y el "ocultismo" de su lenguaje, el saber sólo es accesible a minorías de especialistas, de técnicos $^{32}$. El saber tecnócrático, construido y presentado socialmente como verdad natural, no se manifiesta sólo como una argumentación racional a la cual pueda contraargumentar racionalmente el conjunto de la sociedad, sino que se instituye como símbolo; y éste, a su vez, resulta incomprensible para la mayoría de las personas. Este saber basa la contundencia de su verdad en las formas como ésta es presentada, divulgada y construida. Es una verdad ritualizada, y en cuanto tal el poder instituyente del imaginario social la transforma en símbolo que instituye relaciones de poder pues se impone como aquello que debe ser aceptado por todos aunque no se comprenda su sentido lógico, sino que se acepta en virtud de su poder simbólico.

El saber técnico, transformado en verdad natural, se ha convertido, en nuestras sociedades contemporáneas, en una nueva forma de legitimación simbólica del orden socialmente instituido. Él es una verdad incontestable que se transforma en poder e impone una determinada forma de concebir la realidad. Comprender el saber técnico, es decir, descodificarlo significativamente para desentrañar su sentido, supone despojarlo del poder legitimador que posee. Eso equivale a comprenderlo como significación construida a partir de unos determinados intereses; con lo cual pierde el sentido de verdad objetiva que emana de la naturaleza de las cosas. En ese momento hermenéutico la verdad dejaría de actuar inconscientemente como forma de poder y pasaría de ser invisible a mostrar su verdadero rostro de símbolo legitimador del "estatus quo". La verdad desenmascarada y despojada de su poder legitimador pierde su eficacia como símbolo que se impone de forma invisible, inconsciente y hasta inevitable al conjunto o a la mayoría de la sociedad.

\section{Racionalidad y poder simbólico}

La racionalidad, por sí misma, en cuanto discursividad lógica, no posee el potencial de imponerse de forma inconsciente e invisible al conjunto de la sociedad. Por el contrario, la racionalidad quiere comprender y busca entender

32. "Al volverse asunto de especialistas, (cualquiera que sea el nombre que pueda dárseles: tiranos, burócratas, tecnócratas), la política se convierte en una entidad abstracta, es 'asunto de los demás', 'otro asunto' del cual no tiene caso ocuparse" MAFFESOLLI, Michel, La política y su doble, México 1992, p. 26. Para conocer la función de los técnicos en el marxismo contemporáneo cf. PAZ, O., Courant Alternatif, París, 1972, p. 147 y sobre el saber técnico en la China antigua cf. BALAZC, E., La bureaucratie céleste, París, 1968, Apud, MAFFESOLI, M., La política y su doble..., p. 26. 
los sentidos ocultos. Pero, en el afán por racionalizar toda la realidad, ella misma se transforma en símbolo que esconde un sentido y se im-pone -se pone inconscientemente- socialmente como elemento mítico. La racionalidad que busca desentrañar los sentidos escondidos, deslegitimar los símbolos, descodificar los significados inconscientes, se transforma ella misma en un símbolo inconsciente, portadora de un sentido mítico y legitimadora del orden social que ahora es instrumentalizado racionalmente. Ella se impone en cuanto racionalidad instrumental y nueva forma de poder, no en base a su fuerza argumentativa o lógica, sino porque se ha transformado en símbolo ${ }^{33}$. La racionalidad, por sí misma, en cuanto símbolo que se autolegitima, parece mostrarse incapaz de desentrañar el sentido oculto a través del cual ella misma fue instituida como significación social; se manifiesta impotente para poder deslegitimar el potencial simbólico-mitificador a través del cual ella misma legitima el orden social de la modernidad, y por el cual es elevada a la categoría de símbolo o mito.

La racionalidad -aunque se obstinen en no querer admitirlo y pretendan combatirlo a través de todo tipo de teorías o racionalismos críticos- está incondicionalmente vertebrada por la dimensión simbólica que pretende anular, que incluso convierte la propia racionalidad en símbolo. Lo contrario también se cumple, es decir, que cualquier dimensión simbólica está transida por la racionalidad, la cual hace posible su comprensión. Cualquier intento de simbolismo aracional está abocado irremediablemente a la irracionalidad del fanatismo social, de la superstición alienante y de la alucinación mágica de la irrealidad. La dimensión simbólica y la racional están irremisiblemente correferidas y se coimplican en todo sentido construido y en cualquier significación social creada. Razón y símbolo se necesitan y se excluyen al mismo tiempo. Están encadenados en una convivencia correlacional que impone una necesaria y tensional contradicción coimplicante que hace que toda persona y toda sociedad sean necesariamente mito-lógicos.

En nuestras sociedades racionalizadas y racionalizantes, el empeño por eliminar la dimensión simbólica de la persona y de la sociedad hace que la racionalidad sea como aquel ratoncillo que queriendo salir de la rueda en la que está metido la hace girar constantemente sin darse cuenta de la inutilidad de su esfuerzo, y sólo consigue reforzar el sentido circularmente coimplicante de su acción. La racionalidad se ha mitificado como símbolo: "todo lo verdadero tiene que ser racional, y viceversa todo lo racional es verdadero". Este simbolismo mitificador alcanza su expresión máxima cuando la racionalidad se

33. La racionalidad instrumental se identifica en gran parte con la noción de "acción social con arreglo a fines" que Max Weber acuñó, la cual está "determinada por expectativas en el comportamiento tanto de los objetos del mundo exterior como de otros hombres, y utilizando esas expectativas como 'condiciones' o 'medios' para el logro de fines propios racionalmente sopesados y perseguidos." WEBER, M., Economía y sociedad, México 1979, p. 20. Cf. también HABERMAS, J., La ciencia y la técnica como ideología, Madrid 1986. 
manifiesta en forma de discurso científico: "toda la verdad tiene que ser científica y todo lo científico es verdadero" ${ }^{\prime 34}$. El símbolo de la cientificidad encubre, legitima, las nuevas formas de poder que la sociedad actual instituye. Hace del orden establecido por un saber científico, un orden necesario, natural y fatalmente existente, fuera del cual sólo es posible el caos de los románticos y utópicos soñadores de mundos ideales e imposibles.

\section{El poder simbólico y la praxis}

Un último elemento que queremos extraer de la tupida trama que forma la compacta y espesa red de la legitimación simbólica del poder es la praxis. Aunque la mencionemos en último lugar no significa que sea la menos importante. Por el contrario, su importancia es tal que debemos entresacarla constantemente de entre los diversos nudos de la urdimbre significativa para ir mostrando cómo la praxis interactúa con el poder instituyente de lo simbólico a fin de legitimar el orden y legitimarse como praxis, y cómo esa misma praxis interactúa con la potencialidad creadora de lo simbólico para contribuir a la transformación del orden social a través del desentrañamiento de los sentidos que legitiman el poder socialmente instituido.

Aunque el poder socialmente instituido se fundamenta en un simbolismo socialmente aceptado, aquél no se explica solamente, ni puede reducirse exclusivamente, al simbolismo que lo instituye. El ejercicio del poder genera una realidad propia que condiciona la legitimación del poder: la praxis política. Toda praxis, y específicamente la praxis del poder, condiciona las significaciones sociales instituidas. Éstas no surgen del puro concepto o de la subjetividad ahistórica, por el contrario son fruto de la influencia y del condicionamiento socio-histórico. A su vez, la potencialidad creadora del imaginario social no permite que los condicionamientos sociales, por muy fuertes que sean, se transformen en una determinación del mismo. Siempre existe un potencial innovador, creador, del imaginario social que posibilita la institución de novedad histórica, de nuevas significaciones sociales que hagan posible nuevas formas de sociedad.

El poder condicionador de la praxis es fundamental para la comprensión y la construcción del poder simbólico, así como para la legitimación del poder social. Tanto que la legitimación del poder se genera también por la objetivación que la praxis impone en el constante hacer y auto-hacerse de las personas y de la sociedad. Una vez que la praxis ha creado una relación de poder, la comprensión y explicación de la realidad ya está impregnada de la realidad del

34. Sobre las formas de legitimación del saber, cf. LYOTARD, J. F., La condición postmoderna, Barcelona 1999. Sobre las reglas de legitimación de los juegos de lenguaje científicos cf. cap. 7 "Pragmática del saber científico", pp. 51-56. 
poder. La praxis del poder penetra, permea y modela las significaciones sociales instituidas. El poder instituyente de las significaciones sociales está formado, en gran parte, por el poder instituyente de la praxis. La sociedad y las personas absorben los condicionamientos fácticos de la praxis bajo la forma de las normas y de la normalidad. De esta forma, la praxis produce la realidad y, consecuentemente, su legitimación.

La legitimación simbólica del poder se impone de forma diversa en cada sociedad, dependiendo de los diversos factores que la forman. A pesar de la impetuosidad con que puede imponerse a las personas, la legitimación simbólica no consigue determinar la conciencia de las mismas, ni encerrar de forma absoluta la sociedad en la que se instituye y a la que constituye. El poder instituyente $u$ objetivador del imaginario social que impone la legitimidad simbólica del poder no consigue establecer un cerco total en torno de la conciencia ni de la sociedad, porque éstas están informadas -formando una coimplicación contradictoria- por la potencialidad creadora del mismo imaginario. La persona y la sociedad son, al mismo tiempo, creación constante de sentidos nuevos y conservación permanente de los sentidos instituidos. No es posible instituir de forma determinada ni la conciencia ni la sociedad; así como tampoco ambas pueden existir como flujo incesante de creatividad permanente. El poder instituyente y el potencial creador del imaginario social se coimplican, contradictoriamente, haciendo posible la dinámica incesante de creación e institución de las significaciones sociales que constituyen el ser de toda sociedad y de todo sujeto socialmente instituido. 